\title{
Critical Information Technology Issues in Turkish Healthcare
}

By: Aykut H. Turan and Prashant C. Palvia.

Turan, A. H., and Palvia, P. (2014). "Critical Information Technology Issues in Turkish Healthcare". Information \& Management. 51 (1) 57-68.

Made available courtesy of Elsevier: http://dx.doi.org/10.1016/j.im.2013.09.007

***@@ Elsevier. Reprinted with permission. No further reproduction is authorized without written permission from Elsevier. This version of the document is not the version of record. Figures and/or pictures may be missing from this format of the document. ***

\section{cc) (i) $(9)$}

EY No NO This work is licensed under a Creative Commons AttributionNonCommercial-NoDerivatives 4.0 International License.

\begin{abstract}
:
While the importance of information technology in reducing soaring healthcare costs and enhancing service quality is increasingly being recognized, significant challenges remain in how it is implemented. Although there are a few studies investigating key IT issues in healthcare in advanced countries, there are virtually none in developing countries. We bridge this gap by investigating the critical information technology issues in healthcare facilities in Turkey. These issues are developed based on the opinions of senior hospital managers. The top ten issues include privacy, quality, security, and the implementation of electronic medical records. Further analyses provide additional insights into the results.
\end{abstract}

Keywords: Healthcare | Key IT issues | Turkey | Healthcare information technology (HIT) | Hospital managers

\section{Article:}

\section{Introduction}

Emerging opportunities stemming from the implementation of information technology (IT) and increased competition have forced hospital managers to look for new ways to reduce costs, improve performance, and better serve their patient bases. Greater attention to information technology management issues in the healthcare industry have originated from the role of IT in addressing increasing service complexity, requirements for improving healthcare outcomes, and integrating healthcare delivery systems [47]. IT investment in healthcare is regarded as the driving force behind the reduction of continuously soaring costs and the enhancement of service quality, particularly in developing countries [18]. Healthcare information technologies (HITs) have begun to transform healthcare delivery by improving safety and efficiency, and by creating cost-effective, timely and patient-centered care [67]. In general, however, the adoption rate of information technology in healthcare has remained low, even in advanced nations, compared to other industries in spite of its increasing ubiquity, decreasing costs and potential benefits in 
clinical decision-making processes [15] and [31]. One of the main reasons for this phenomenon is the unique structure of the healthcare industry: healthcare institutions differ from other businesses in terms of their operational independence and individual autonomy [36]. In healthcare organizations, physicians generally have more autonomy, and healthcare payment systems usually do not compensate physicians based on the quality of care they provide. Furthermore, healthcare participants are generally not rewarded for learning and adopting new systems designed to improve the quality of service.

All over the world, healthcare systems are threatened by continuously soaring costs and demand, inconsistent and low-quality care, and poorly coordinated healthcare services[40]. Healthcare spending in every nation is increasing. By 2017, total healthcare spending in the U.S. is expected to reach $20 \%$ of GDP, or US\$4.3 billion, with a 7\% annual average increase [55]. At the same time, governments around the world are trying to find ways to address the inefficiencies and high costs of providing healthcare to their citizens. In this respect, information technology is regarded as a savior by healthcare providers promising to reduce costs and enhance service quality. However, while IT alone cannot solve all of the problems in healthcare, such as high costs, poor safety and quality, and a largely uninsured population, these problems cannot likely be solved without IT [17]. IT offers many benefits and can give healthcare professionals a greater ability to streamline and standardize processes, as well as to access, share and analyze healthcare and patient information to address the above-mentioned issues [17].

IT investments and the importance of the role of IT in healthcare have steadily increased in advanced countries in recent years [2]. While there is a growing number of publications on IT implementation in healthcare in advanced countries [20], [53] and [64], scientific studies in developing countries are limited. To bridge this gap, this study investigates the critical information technology issues in healthcare facilities in Turkey, a developing country. Due to the nature of the health workforce (largely auxiliary personnel) and limited available interventions, health systems and health professionals in developing countries need much more information than those in developed countries, yet they have limited access to evidence-based decisionmaking tools and support [54]. Efficient access to financial, technical and healthcare information plays a crucial role in improving the living standards of poor people in developing countries. Information technology is the primary enabler in improving access to information and evidencebased decision making. By better understanding the key IT issues, managers of healthcare institutions can make better decisions about healthcare IT investments and adopt effective technologies for their organizations. In addition, high-level policy makers and government officers can define better strategies and policies for their countries' healthcare systems. Understanding the perceptions of senior managers about key IT issues is usually the starting point in this exercise (e.g., [3], [42] and [43]). Therefore, this study answers the following question: what are the key and pressing IT issues in the Turkish healthcare system from the point of view of senior managers?

The choice of Turkey for this study is important for several reasons. First, Turkey is a developing country. Although the importance of information technology in Turkish healthcare has been realized and promoted since the beginning of this decade [14], the amount of IT investment in Turkish healthcare has remained much less than $1 \%$ of the total investment in healthcare, yet the same figure could easily rise above $3 \%$ in advanced nations [7]. Logistical and geographic 
barriers intensified by financial hardships usually make healthcare unaffordable for much of the population in developing countries [35]. Information and communication technologies have the potential to reduce these barriers by eliminating physical distances, enabling the sharing of limited health resources, and making healthcare affordable and widely available to much of the deprived population. As discussed in detail in later sections, the Turkish Ministry of Health initiated the Turkish Healthcare Transformation Program (THTP) in 2003 to achieve effectiveness, efficiency and equity within the organization and in the delivery and financing of healthcare services. Sahin et al. [57] confirmed that after the THTP implementation, the productivity of Turkish hospitals improved significantly. Much of this improvement can be credited to the widespread implementation of HITs.

Additionally, Turkey is in the process of becoming a member of the European Union (EU) and has served as a bridge between East and West for many centuries. It has an emerging economy with high growth rates in its GDP per capita. Turkey is predominantly Muslim yet secular. Therefore, defining and evaluating key technological issues in Turkish Healthcare would provide appropriate and valuable lessons for other developing and emerging economies in the allocation and use of limited IT resources.

The article is organized as follows. The next section describes the underlying characteristics of the Turkish healthcare industry, which is followed by a methodology section. The results, analyses, and discussion are then presented, and the final section concludes the paper.

\section{Turkish healthcare}

As a developing country, the Turkish healthcare industry has unique characteristics compared to healthcare in advanced nations. The Turkish healthcare system has a highly complex structure in which the Ministry of Health, universities and private organizations provide healthcare to patients [50]. Overall, although continuously increasing, the percentage of GDP allocated for healthcare in Turkey is below that of advanced countries. In 2007, Turkey spent approximately $6 \%$ of GDP on healthcare, according to the Turkish Statistical Institution [61]. All Turkish residents have basic public healthcare insurance. According to the Turkish constitution, "Everybody has the right to have social security", and the same provision states that the Turkish government takes necessary measures to ensure social security and the establishment of necessary social security institutions [22]. In addition to state-owned funds, there are private funds for supporting social welfare for employees, particularly those employees working in financial and manufacturing organizations. Turkey has one of the highest per capita expenditures on social welfare services in the world [16]. Traditionally, the government largely provides and pays for all healthcare services because the country has a limited number of social and nongovernmental organizations to shoulder the responsibility. The basic international health service indications, such as infant mortality rate, are continuously improving. Thanks to special government-funded programs that have been in place since the 1960s, the country has progressed a great deal, especially in providing preventive healthcare services, thereby improving its healthcare measures significantly[22]. Moreover, Turkey has a relatively young population. With adequate support, this young population would be a great asset for the healthcare industry. Generally, the major hospitals have adequate instruments and technological infrastructure. Newly established private hospitals are charging competitive prices and offer high-quality 
advanced services. Therefore, private hospitals have begun attracting patients from Europe and the Middle East [16].

However, Turkey has some potential weaknesses. Although there have been significant recent improvements in Turkish healthcare, the country still lags behind OECD member countries in terms of basic healthcare indicators, such as the number of physicians and nurses per capita [16]. While healthcare expenditures averaged 6.3\% of GDP in 2006, Turkey still lags behind other European countries whose healthcare expenditures average $8.9 \%$ of GDP [16]. Healthcare services are provided under strict guidance and monitoring by the Ministry of Health. However, healthcare policies are usually defined by populist approaches without reference to real problems and the needs of the country. Furthermore, the traditional structure and culture of health institutions pose obstacles to the development of institutions and the enhancement of services. The general problems in Turkish healthcare are mostly due to adoption and policy. Healthcare providers and policy makers are far from being able to offer large and comprehensive solutions to the country's healthcare problems [60]. Additionally, there exist integration and coordination problems in investment and management. Finally, Turkey spends a significant amount of money on its military due to its risky geo-political position, thereby limiting the money it can invest in healthcare.

Turkey is not a wealthy country. At the national level, funds allocated to IT investments remain limited. Investments in IT are not only inadequate, but are not planned or coordinated effectively. Furthermore, the country depends largely on foreign suppliers for medicine, healthcare equipment and technical infrastructure. IT hardware and software infrastructure is largely imported and purchased from foreign suppliers. Government guidance and monitoring are limited in this process.

Nevertheless, the Turkish healthcare system is going through an intensive transformation to satisfy EU membership requirements and harmonization processes. Crucial reforms have been carried out in recent years [62]. Turkish healthcare is beginning to take on market-oriented characteristics, such as competition and choice, and patients can now choose among public and private healthcare providers [1]. The major objectives of these reforms are reducing inequality in access to healthcare and narrowing the gap in the use and quality of healthcare services [62]. The Turkish healthcare system was unified in October 2008 with the initiation of the Universal Health Insurance System (UHI) and the implementation of various social security systems under one large umbrella to cover all citizens [50]. With the use of citizen identification numbers in the new health information system, all patient records are now easily accessible. In addition, there is a plan underway to issue credit card-like social security cards to employees that can be swiped to provide hospitals and pharmacies with insurance details [50].

THTP aims to provide better quality information to managers and public officials to make sound policy and administrative decisions [62]. THTP plans to establish a nationwide integrated healthcare information management system. The first tender was made in 2007 and tests of the system began in 2009. The system is called "Sağlık Net" and as of 2012 was largely operational, according to IT experts at the Turkish Ministry of Health. ${ }^{1}$ The Health Ministry collects a variety of health data from public and private hospitals. However, because the legislative framework is not yet ready, the Ministry cannot share and use the collected data. Furthermore, the doctors and 
health personnel are not yet fully collaborating, and the data quality is poor. Note that THTP faces unique problems of healthcare provision in developing nations, such as the expansion of coverage, the improvement of access to services, and the combating of informal practices and corruption [1]. Despite these challenges, the transformation program is progressing well.

\section{Research methodology}

There is a rich tradition of identifying key IT issues in the information systems (IS) literature going back to the early 1980s [9] and [19]. In recent years, Luftman and his colleagues published key IT issues studies on an annual basis [42], [43], [44] and [45]. However, the study of key IT issues in the healthcare industry is limited, even in advanced countries. This study is based on a recent study on the healthcare industry in the U.S. [53]. The key issues survey instrument was adopted from the Palvia et al. study[53] and modified for the Turkish context. In the process, the authors made an extensive review of the complete instrument and a number of changes for the Turkish context. The English survey was translated to Turkish by one of the authors and then translated back to English by an expert working in the industry. During the process, several modifications were made. For example, the item (i.e., an issue) "IT Human Resources Development" in the original survey was divided into three items: training for IT personnel, training for healthcare personnel and training for administrative personnel. "Using IT to empower patients" was modified to "Using IT to enhance patients' rights". "IT's role in healthcare outsourcing" was reconfigured as "IT's role in privatization of Turkish healthcare". "IT's role in off-shoring" was completely dropped. "Improving productivity in healthcare organizations" and "Alignment between medical staff and administrative staff policies and strategies" were added. The job titles of participants were defined according to Turkish practices. Instead of service type, we classified hospitals based on three prevalent categories.

A five-person expert panel working in healthcare was formed and requested to evaluate the survey. The panel members were a Baş Hekim (equivalent to a CEO at Turkish Hospitals), a department head and a hospital manager at a university hospital, and two medical doctors working in private hospitals with managerial duties as division heads. The panel members commented on the clarity and completeness of the survey. Some of the items were rewritten to include more explanation for the Turkish context. Because the survey was only being shared with mostly healthcare staff at that point, we decided to obtain feedback from IT professionals. Therefore, prior to the full-scale implementation of the survey, the instrument was pilot tested with five hospital IT managers. They agreed with the questions and acknowledged that the best responses to these issues could only be provided by the CEOs and general managers of Turkish hospitals. Only minor editing changes were made at that point. The final 36 issues included in the instrument are presented in Table 1. They are listed in no particular order. 


\section{Table 1}

Information technology issues in Turkish healthcare.

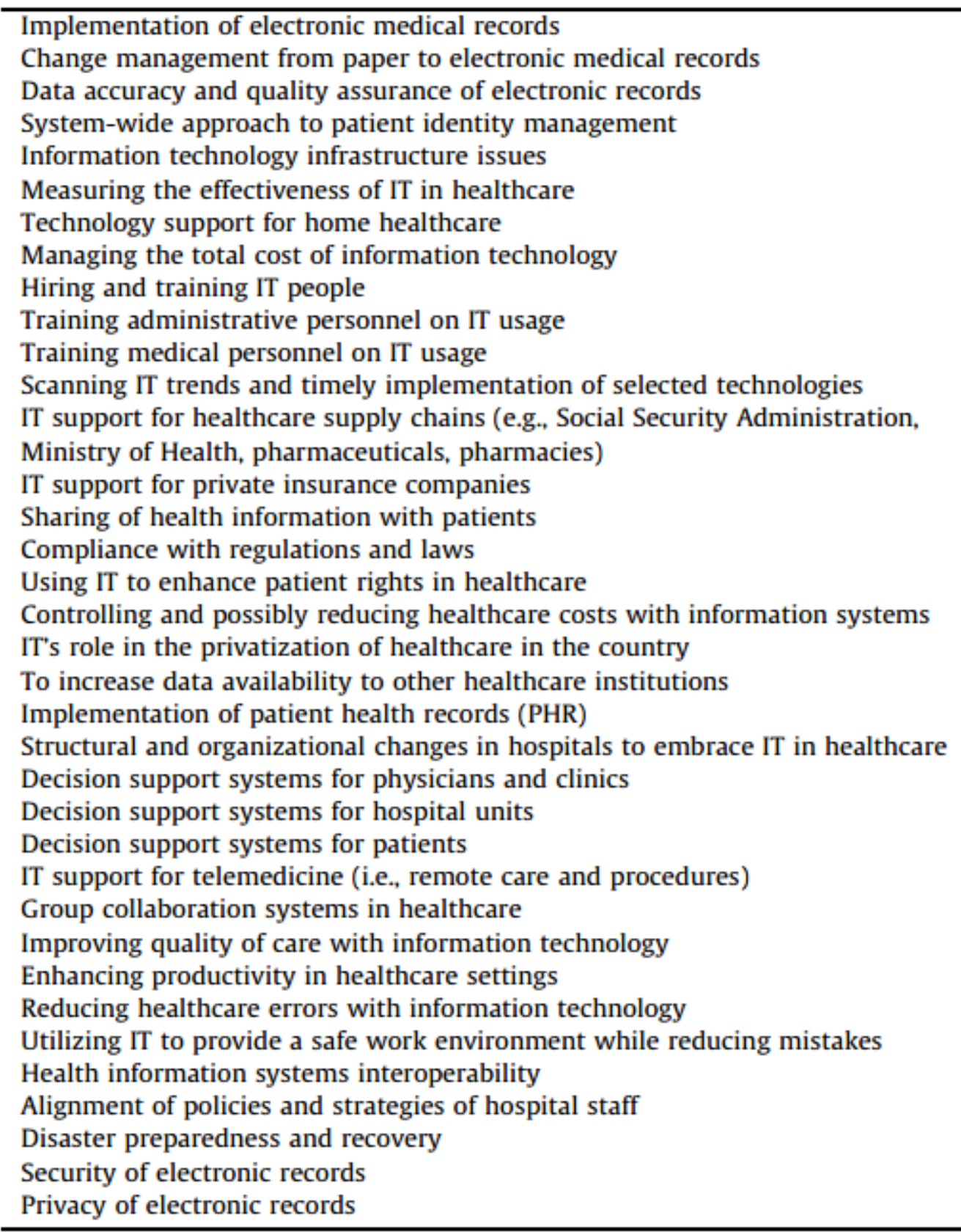

The key issues were incorporated in a questionnaire that also included items for assessing hospital culture, general management philosophies of hospital senior managers, and questions on organizational and individual characteristics of the respondents. The questionnaire was completed by CEOs (Baş Hekim), vice CEOs (Baş Hekim Yrd.), general managers (Müdür), assistant general managers (Müdür Yrd), and IT managers (Bilgi Işlem Md). The respondents were asked to rate each issue on a 7-point Likert scale, where 1 represented the highest importance and 7 represented the lowest importance. The study was carried out with the support of the Turkish Ministry of Health. An online survey was posted on the university website of one 
of the authors and announced officially to over 900 public hospitals run by the Ministry of Health and approximately 100 additional private hospitals in the country.

Official permission to administer the survey was obtained from the Ministry of Health. The survey was posted on the university website of one of the authors, as it was a requirement of the Ministry that the survey be posted on a .tr extension website. A survey link with an embedded password was created and shared with the Ministry. The Ministry's IT department distributed the survey throughout the country via official channels. The Ministry did not permit the authors to be involved in the survey distribution and administration process. Because the Ministry was only able to distribute the survey to public hospitals, the CEOs, vice CEOs and hospital managers of private hospitals (approximately 100 in total) were personally called by one of the authors inviting them to participate in the survey.

\section{Sample and respondent characteristics}

Ninety-one complete and useful responses were obtained from senior management-level employees. Managerial levels in Turkish hospitals are mainly divided into two professions. The first managerial level is called "Baş Hekim". This person is a medical doctor and is equivalent to a CEO in the American hospital system. The Baş Hekim is responsible for all managerial aspects of the health organization and oversees its general operations. He has a number of assistants, who are called "Baş Hekim Yardımcısı" and are also medical doctors. The Baş Hekim Yardimcisı are roughly equivalent to vice CEOs. The second managerial level is composed of non-medical professional managers. This group has a number of deputies who help them manage and carry out administrative tasks. They are called "Hastane Müdürü" and "Hastane Müdür Yardımcisı". We were also interested in getting input from managers who are in charge of Information Technology operations in their hospitals. Therefore, we included another managerial position, that of IT Manager (Bilgi İşlem Müdürü in Turkish) in the survey. Turkish healthcare organizations generally do not hire or employ a senior individual to manage IT (equivalent to a CIO position). Ultimately "Baş Hekim" and, in some cases, "Hastane Müdürü" make decisions related to information technology investments. Even if some Turkish hospitals have IT departments, they largely function as technical service providers. Hence, our sample includes only a small percentage of participants who identify themselves as IT managers per se. Nevertheless, it is widely argued and accepted that physician leadership is critical to the success of HIT investments [38] and [47]. Moghaddasi and Sheikhtaheri [47] even predict that, in the future, $\mathrm{CIO}$ and CEO positions may merge in healthcare settings. Thus, our sample, which was composed predominantly of physician administrators, provides a sound understanding of the key healthcare IT issues in Turkish hospitals.

Table 2 shows the sample characteristics. The majority of the responses came from CEOs, followed by vice CEOs. Of all of the respondents, 36\% are non-medical managers and the rest $(64 \%)$ have a medical background. Approximately $81.4 \%$ of the respondents are CEOs, vice CEOs and hospital managers involved in strategic decision making and policy formulation. Approximately one quarter $(30.7 \%)$ of the managers said that their hospitals are part of a larger healthcare system. Most hospitals are stand-alone entities, not affiliated with another system or corporation. A large number of respondents (79\%) said that they are from public institutions. Most respondents (70\%) were from urban hospitals. In Turkey, a significant number of 
healthcare facilities are located in urban areas. Given the lack of resources, only a limited number of services are available in rural areas. Turkish hospitals are classified into three stages or categories. The first-stage health providers are small health clinics that do not provide inpatient services. The second-stage health providers are hospitals that provide all or a majority of healthcare services, including inpatient services. Finally, third-stage health providers are large hospitals with inpatient services and research facilities. These third-stage hospitals also offer residency programs. Quite a large proportion of participants classified themselves as secondstage hospitals $(70.8 \%)$. Note that our sample represents the larger hospitals in Turkey. Nationally, Turkish hospitals are predominantly public (approximately 65\%) and are mostly urban. $^{2}$

Table 2

Sample characteristics.

\begin{tabular}{lcclcc}
\hline \multicolumn{5}{c}{ Total sample size: 91 } \\
\hline & $N$ & Percent & $N$ & Percent \\
\hline Position & \multicolumn{5}{c}{ Ownership of the organization } \\
CEO & 30 & 34.9 & Public & 72 & 79.1 \\
Vice CEO & 25 & 29.1 & Private & 19 & 20.9 \\
Manager & 15 & 17.4 & Location of the organization \\
Assist. Man. & 13 & 15.1 & Urban & 63 & 70.0 \\
IT Manager & 3 & 3.5 & Rural & 27 & 30.0 \\
Whether offering residency & program & Type of healthcare organization \\
Yes & 9 & 10.3 & First stage & 11 & 12.4 \\
No & 78 & 89.7 & Second stage & 63 & 70.8 \\
Being part of a larger hospital system & Third stage & 15 & 16.9 \\
Yes & 27 & 30.7 & & & \\
No & 61 & 69.3 & & & \\
\hline
\end{tabular}

Note: Some numbers may not add up to 91 due to non-reporting.

Managers seem to have a wide range of experience in healthcare management, ranging from 0 to 40 years (Table 3 ). Additionally, managers reported that they had spent a large part of their career in their current positions. Hospital size can be measured by the number of employees and number of beds. Again, these are mostly larger hospitals. However, the number of hospital employees ranged from 6 to 2300 and the number of beds ranged from 0 to 1000 .

Table 3

Professional characteristics and hospital service characteristics.

\begin{tabular}{llrr}
\hline Characteristics & Minimum & Maximum & St. Dev. \\
\hline Number of years in healthcare management & 0 & 40 & 9.65 \\
Number of years at current position & 0 & 30 & 6.29 \\
Total number of employees & 6 & 2300 & 12.78 \\
Total number of beds & 0 & 1000 & 306.96 \\
\hline
\end{tabular}

\section{Top ten information technology issues}

The average rating of each issue was computed for all of the respondents. Note again that the Likert scale ranged from 1 to 7 and a lower average represented a higher ranking. Based on the 
average responses, the top ten IT issues in Turkish healthcare are reported in Table 4 and are discussed in more detail below.

\begin{tabular}{|c|c|c|c|}
\hline Rank & Issues & Average rating & Standard deviation \\
\hline 1 & Privacy of electronic health records & 1.57 & 1.53 \\
\hline 2 & Quality assurance of electronic health records & 1.60 & 1.54 \\
\hline 3 & Security of electronic health records & 1.65 & 1.58 \\
\hline 4 & Implementation of electronic medical records & 1.73 & 1.68 \\
\hline 5 & System-wide approach to patient identity management & 1.75 & 1.52 \\
\hline 6 & Change management from paper to electronic medical records & 1.83 & 1.56 \\
\hline 7 & Implementation of patient health records & 1.87 & 1.64 \\
\hline 7 & Compliance with regulations and laws & 1.87 & 1.71 \\
\hline 7 & Reducing healthcare errors with information technology & 1.87 & 1.59 \\
\hline 10 & Enhancing productivity in healthcare settings & 1.88 & 1.54 \\
\hline
\end{tabular}

\subsection{Privacy of electronic health records}

The privacy of electronic records was rated as the most important issue by Turkish healthcare managers. There is a significant amount of risk involved in presenting, sharing and storing personal information in electronic media, particularly over the Internet. As Gostin [28] argued, the privacy of patient health information is an important issue in healthcare. Particularly in developing countries, there is virtually no or insufficient legislation safeguarding patients' personal health information [13]. Because of the ease of access and data transfer, electronic documents pose tremendous privacy and security risks. Given that sensitive personal information, such as contingency diseases, drug abuse, and emotional problems may be accessed via personal health records, it is necessary to maintain strong measures to protect patients from privacy violations. Article 20 of the Turkish constitution assures the secrecy of a person's private life. Additionally, the Turkish Patient Lives Code, dated 01.08.1998 and numbered 23420, amalgamates all of the country's regulations regarding the privacy of personal health records. Nonetheless, there is still a perceived risk to privacy in the current efforts to gather healthcare information under one integrated system as proposed by the Ministry of Health.

\subsection{Quality assurance of electronic health records}

Quality assurance of health records is an important issue in developing countries [23]. Healthcare workers' capacity and willingness to produce quality and relevant health records is crucial to improving the quality and performance of healthcare services [66]. Furthermore, healthcare IT investments are largely justified by the promise of high-quality medical records [53]. Because Turkish healthcare managers and policy makers adopted a piecemeal approach to healthcare information management, and because health-related information is managed within a variety of non-integrated systems, it is difficult to access accurate and high-quality information throughout the system [56]. A limited number of qualified physicians with large workloads has resulted in the widespread employment of healthcare assistants or secretaries who are in charge of collecting and storing healthcare information during patient visits. In addition, larger workloads decreases the amount of time that doctors can devote to patients, in turn decreasing the emphasis on quality assurance of healthcare records. Turkish healthcare management is not always information-based and much of the coded information is inaccurate or incomplete. Thus, the information cannot be used effectively by healthcare managers. There is no authority or mechanism in place to assure the quality of information, and there is not much integration or information sharing among 
governmental bodies or even within the Ministry of Health. Thus, reliable access to and accuracy of information poses serious problems and issues for healthcare managers.

\subsection{Security of electronic health records}

The security of electronic health records was identified as the third-most important issue by hospital managers. Healthcare organizations collect, transmit, maintain and store vast amounts of information electronically. Electronic medical records are becoming pervasive in Turkey. Security threats to electronic health records can be intentional or unintentional, with the people able to access them hailing from both inside and outside of the organization. Such threats can also be technology-related, such as the failure of the IT department with no adequate backup to take its place. Security threats can also be environment-related, such as floods, ${ }^{3}$ earthquakes and fires. Therefore, healthcare organizations must protect their systems and healthcare records from a variety of potential threats, including viruses, fires, untested software, and theft of clinical or administrative data, as well as intentional or unintentional damage to or misuse of organizational hardware, software and data [63]. Sound procedures and software/physical safety measures should be implemented to maintain their integrity and security. Furthermore, the intentional or unintentional release of patient-specific information can cause security breaches. Equally important is for healthcare organizations to maintain a balance between security and data availability [63]. Unnecessarily stringent measures may prevent legitimate data access, which in turn could reduce healthcare service quality. Overall, Turkish healthcare managers have only recently realized the importance of securing their electronic health records. Hence, policies and procedures for protecting security are largely missing or evolving at this time.

\subsection{Implementation of electronic medical records (EMR)}

Electronic medical records (EMR) are application environments composed of clinical data repositories, clinical decision support systems, controlled medical vocabulary, order entry, computerized order entry, pharmacy and clinical documentation applications to support patient care and provide healthcare professionals with tools to document, monitor and manage healthcare delivery [27]. "Electronic Medical Records are electronic health related information of an individual that can be created, gathered, managed and consulted by authorized clinicians and staff within one healthcare organization" ([63, p. 5]). EMRs are created by individual health organizations and serve as the source of electronic health records (HER). Electronic health records, on the other hand, are created, managed and consulted by health personnel across a number of healthcare organizations. EMRs are seen as central to creating integrated HITs [40]. They are the centerpiece of providing better healthcare to individuals and are the backbone of computerized health information systems. They can effectively reduce medical errors and improve the quality and efficiency of patient health services [27] and [48]. However, it is not easy to implement EHRs or EMRs. The implementation barriers can be classified under three categories: financial, organizational or behavioral, and technical [63]. Financial barriers included a lack of financial or capital resources needed to develop, acquire, implement and support healthcare information systems. Organizational or behavioral barriers are related to the use and acceptance of systems by healthcare personnel. Finally, technical barriers are related to a lack of technical capabilities, and a lack of definitions and standards for interoperability. As Turkish health organizations move rapidly toward electronic environments, EMRs have become the focus 
of administrative processes. Currently, the Turkish Ministry of Health is in the process of creating a country-wide electronic health management system, and EMRs are critical to this process. According to an IDC Health Insights report, the amount of money Turkish health organizations have spent implementing EMR systems is expected to double by 2015 from US $\$ 1.9$ billion to US\$3.8 billion [10].

\subsection{System-wide approach to patient identity management}

In Turkey, each healthcare facility uses its own system. This localized data network inhibits the sharing of patient information and the adoption of a system-wide approach to patient healthcare management. The majority of healthcare data is stored on paper in different geographical locations, thus hindering and limiting adoption of system-wide approaches to healthcare management. If a patient is treated in a city where the hospitals have advanced electronic health management systems and then receives treatment in a different city, most of his personal and health information will have to be reentered or recreated. Almost all of the medical tests will need to be done again, causing significant additional expense and burden to either the patient or the social security system. Adopting a system-wide approach to patient identity and health management has important benefits ranging from the ability to offer better and less costly health services to enabling complete and extensive data resources for researchers and decision makers. However, incompatible infrastructures, industry capacity, and lack of security and standards are major challenges to adopting a system-wide approach to patient healthcare management [12]. System-wide standards can facilitate and accelerate the adoption of new HIT by enhancing compatibility, ensuring HITs works for all stakeholders, expanding the value of the network and reducing switching costs [15]. Yet, system standardization can support heterogeneity in healthcare across medical conditions and among patients.

\subsection{Change management from paper to electronic medical records}

Like many IT implementations, most of the healthcare information systems applications have not been completely successful [41]. According to research estimates, technical factors explain between 5\% and 20\% of HIT implementation failures [40]. Social and organizational factors are the main reasons behind the failures of HIT implementations. Every new implementation brings change, whether in expectations or the way tasks should be completed. It is not uncommon for people and employees to resist change. Lewin [39] argues that social systems are like biological systems, which have the tendency to maintain the status quo by resisting change and reverting back to the original state. Resistance to IT implementation and adoption by physicians is a common phenomenon in healthcare [11]. Resistance can be irrational or self-serving, yet it is an important form of feedback [25]. Traditional change management techniques, such as software demonstrations, user trainings and help desk staffing in implementation have had limited success overcoming user resistance [11]. Users' negative perceptions of usefulness and threats can have negative impacts on adoption intentions and may boost resistance behaviors. Therefore, it is imperative that healthcare managers understand all aspects of physicians' expectations and perceptions and address them adequately before, during, and after implementing new health information systems.

\subsection{Implementation of patient health record}


The implementation of patient health records is tied with the following two issues for seventh place. The terms "Electronic Health Records" and "Patient Health Records" are sometimes used interchangeably and evaluated accordingly [27]. Although related, they encompass different concepts. Patient or Personal Heath Records (PHRs) are electronic records of health-related information on an individual that conforms to nationally recognized interoperability standards and can be drawn from multiple sources. Additionally, they can be managed, shared, and controlled by the individual [63]. EHRs, however, are created, managed and consulted by authorized clinicians and staff across more than one healthcare organization [63]. PHRs are crucial to the successful implementation of electronic health management systems while reducing costs and improving healthcare. PHRs depend on the effective use of EMRs. At the same time, EMRs could not reach their full potential without the proper implementation of EHRs [27]. While EMRs are created by individual healthcare providers, PHRs are healthcare information shared across healthcare facilities by all stakeholders in the system of a region or country. In addition to enhancing healthcare delivery quality and reducing delivery costs, PHRs promote communication, responsibility and data usage between healthcare stakeholders [67]. In Turkey, the implementation of EHRs (and by implication, PHRs) is part of the electronic transformation endeavors of the Turkish government. According to the Knowledge Society Action Plan [21], a plan to create a nationwide Health Information System has been initiated with the participation of the Health Ministry, Social Security Administration, Turkish Statistical Institute, Turkish Standards Institution, Scientific and Technological Council of Turkey, and related institutions and non-governmental organizations. Currently, the preparation of Turkish egovernment and knowledge society laws is in progress. These laws are expected to shape the legislation framework for the EHR and PHR implementation process. Yet, the widely acknowledged barriers to the effective use of PHRs by patients and physicians are privacy and security, costs, standards, and interoperability [67]. These barriers are also significant in Turkey. Because PHRs may threaten ethical values, such as privacy, confidentiality, and perceptions of medical record integrity, the use and benefits of PHRs may not be distributed equally among the larger population. Thus, the implementation and adoption of PHRs may lag behind the expectations and desires of policy makers and purchasers of these systems.

\subsection{Compliance with regulations and laws}

The Turkish healthcare system is complex and fragmented, involving a number of government agencies and regulatory bodies [50]. Although extensive efforts are in place to integrate and consolidate the Turkish healthcare system, there are different laws and regulations in place to guide the practice. Er [24] lists sixteen major and fundamental laws about Turkish health management and twenty special laws. In addition, there are numerous regulations and decrees. There is little standard and uniformity among Turkish Healthcare legislation. Most laws and regulations have been enacted because of political considerations, not because of logical requirements or necessities. This causes widespread disorder among practitioners because they cannot foresee the future consequences of their actions. While Turkey is now creating the necessary underlying framework of legislation for electronic healthcare management systems, the current reality indicates turmoil. Almost every healthcare process creates some legislative outcomes and involves some sensitive and personal information. Although advanced western societies are generally more conscious of the rule of law and of compliance with laws and regulations, the level of consciousness appears to also be steadily increasing in Turkey. In 
particular, given Turkey's continuous efforts to harmonize its laws and regulation to those of the EU in preparation for EU membership, complying with existing laws and regulations in all areas of administration has become important.

\subsection{Reducing healthcare errors with information technology}

Death resulting from preventable medical mistakes is one of the top five causes of death in the healthcare system [5] and [6]. Medical errors are common in healthcare systems throughout the world. Statistics indicate that between 44,000 and 98,000 people die in the U.S. each year due to medical errors. The same figure is approximately 40,000 in England, between 5000 and 10,000 in Canada, and 25,000 in Germany [49]. A recent study of Turkish healthcare professionals revealed that more than $6 \%$ of participants admitted that they had made at least one mistake that endangered a patient's life and more than $10 \%$ acknowledged seeing their colleagues make mistakes [49]. The same study indicated that more than $50 \%$ of healthcare staff also make such mistakes. Information technology has the potential to reduce errors and improve patient safety due to improved and efficient record keeping as well as to provide access to more current and remote patient records [53]. At the same time, IT can introduce unintended consequences and increase certain types of errors. Called e-iatrogenesis by Weiner et al. [65], it is defined as patient harm caused at least in part by the application of health information technology.

\subsection{Enhancing productivity in health settings}

Productivity problems are the major barriers facing the development of Turkish healthcare. Because most of the healthcare in the country is provided by public hospitals and staff employed by the government, often mired in bureaucracy, low productivity is very common throughout the healthcare system. Lifelong employment, lack of incentives based on performance and widespread organizational stagnancy and red tape are the major reasons for widespread unproductive operations in Turkish public organizations. One of the major indicators of efficiency in healthcare organizations is the bed utilization rate. This figure is approximately 55\% in Turkish hospitals [51]. IT can improve operations as well as the decision making abilities of managers by providing current, complete and relevant information in a timely manner. Furthermore, health IT is expected to transfer Turkish hospitals from their current bureaucratic hospital management approach to a more productive patient management approach using a participative management style [52]. Thanks to the Turkish Health Transformation Program referred to earlier in this paper, hospitals can invest in IT and have the potential to enhance productivity. However, hospitals do not seem to be improving their overall performance[57]. This may be due to top managers' inadequate understanding of the significant role IT plays in improving performance and their lack of motivation to improve productivity.

\section{Bottom ten information technology issues}

It is instructive to examine the bottom IT issues to get a sense of what is not important to Turkish healthcare administrators. The bottom ten issues are reported in Table 5. Some comments are in order. 
Table 5

\begin{tabular}{llll} 
The bottom ten issues. & & \\
\hline Issue rank & Issue & Average rating \\
\hline 36 & IT support for telemedicine (i.e., remote care and procedures) & 3.54 & Standard deviation \\
35 & IT's role in privatization of healthcare in the country & 3.06 & 2.97 \\
34 & Technology support for home healthcare & 2.97 & 1.87 \\
33 & IT support for private insurance companies & 2.68 & 1.97 \\
32 & Sharing of health information with patients & 2.54 & 1.70 \\
31 & Using IT to enhance patient rights in healthcare & 2.36 & 1.57 \\
30 & Measuring the effectiveness of IT in healthcare & 2.34 & 1.69 \\
29 & Decision support systems for patients & 2.27 \\
28 & Group collaboration systems in healthcare & 1.59 \\
27 & Decision support systems for physicians and clinics & 1.56 \\
\hline
\end{tabular}

Telemedicine is at the very bottom of the list. The potential of telemedicine has not been exploited even in advanced countries. With Turkey being a developing country, its institutions and residents have only recently begun enjoying the benefits of IT and the Internet. Thus, telemedicine is simply not a major concern at this time. The privatization of healthcare is also not a major issue in Turkey because it has adopted the "public insurance model" under which the Turkish government provides all of the required healthcare services in the country. Notably, however, while private insurance carriers are not widespread, their numbers are growing. The low need for home healthcare can be explained by the collectivistic nature of Turkish society in which there is a high interdependency among members [34]. Turkish people are expected to take care of their elderly and sick, and home care is largely provided by the relatives of the patient. The low importance of "sharing of health information with patients" can be explained by another of Hofstede's [34] cultural dimension of power distance. Turkey ranks high with regard to power distance, which is the extent to which the less powerful members of a society expect and accept that power is distributed unequally. Thus, Turkish systems are hierarchical, and superiors are usually perceived as inaccessible. Turkish physicians are usually considered as the final and utmost authority on health issues and are not expected to share information with their patients. In this role, patients usually assume an obedient role. It is interesting to note that this issue is in conflict with the previously described issue of "patient health records". While the need for PHRs may be articulated by administrators, Turkish culture may actually stand in the way of its implementation. Similarly, using IT to enhance patient rights did not make it into the top issues because patients are in subservient roles and because Turkish hospitals do not practice a patientcentered approach.

A large proportion of Turkish healthcare organizations is owned and operated by the government. Not surprisingly, measuring effectiveness is a low-ranking issue. In this environment, most healthcare managers adopt only conventional methods and do not take much risk. Thus, healthcare managers are not eager to implement new HIT innovations, such as decision support systems, group collaboration systems and emerging technologies. As stated earlier, the strong autonomy enjoyed by physicians and medical staff, and the weak position of consumers do not encourage the adoption of such innovations.

\section{Key issues, entrepreneurial orientation and organizational culture}

When evaluated in the context of entrepreneurial orientation and organizational culture, Turkish healthcare top managers' perceptions of key HIT issues may make more sense and provide additional insights. As a developing country and a Muslim nation, Turkish organizational culture and entrepreneurial orientation have unique features compared to Western organizations. In fact, 
many would argue that Turkish organizational culture and entrepreneurial orientation have both Eastern and Western values due to the location and mindset of the nation. Surely, in making strategic or even day-to-day decisions, top Turkish healthcare managers would be influenced by both the prevalent national and organizational culture as well as the entrepreneurial orientation of the organization.

By using existing validated measures [46] and [59], the entrepreneurial orientation of hospital executives and the culture of their hospitals were captured. Fig. 1 shows their average entrepreneurial orientation on several attributes. These scales range from 1 to 7 , as shown.

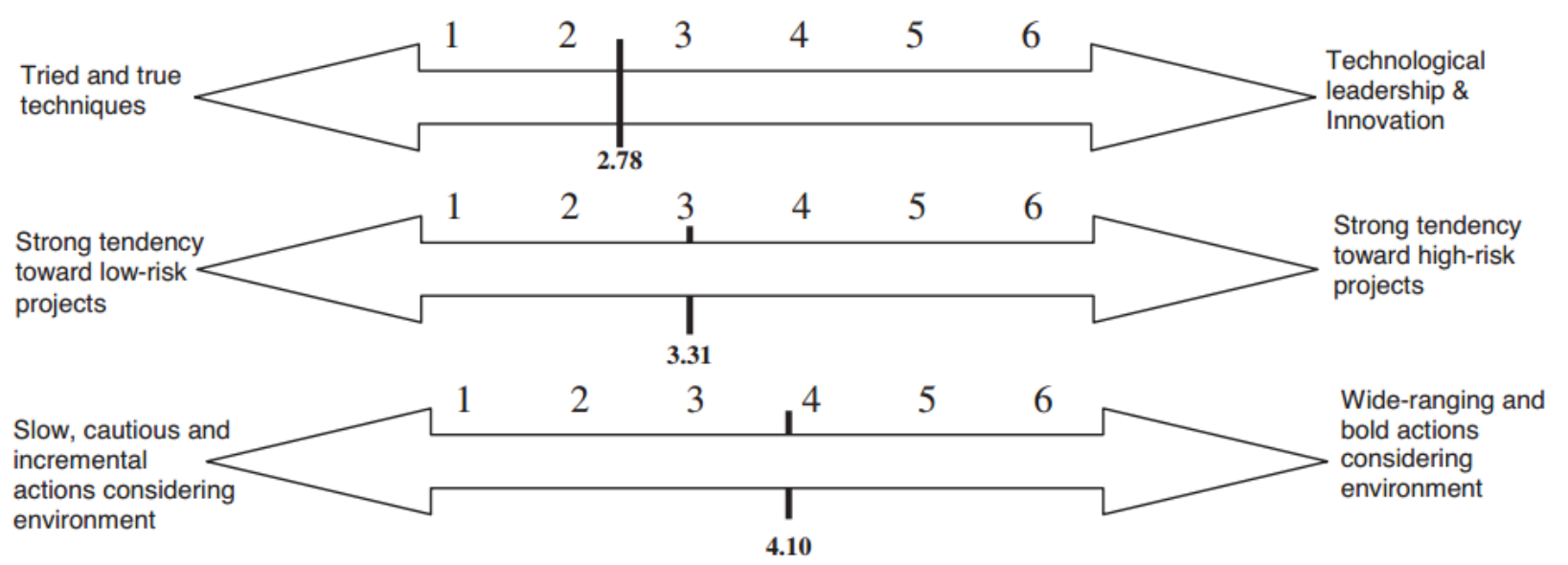

Fig. 1. Entrepreneurial orientation of Turkish hospital administrators.

It is apparent that Turkish healthcare managers tend to adhere to tried and true marketing principles rather than adopting non-standard and innovative practices. Because most survey participants were managers at Turkish public hospitals, there is very little incentive to be innovative. For the same reasons, survey participants expressed a strong tendency for low-risk projects over high-risk ones. In other words, senior management tends to be conservative and risk-averse. However, senior management seems to be a little more entrepreneurial when accounting for environmental conditions. These results are not surprising given the existence of outdated, bureaucratic, limited or non-incentive-based and risk-averse nature of Turkish public administration. These findings can be contrasted with findings from the U.S. [53]. While American hospital executives were also conservative, their Turkish counterparts were far more conservative and risk-averse. In addition to the public ownership of Turkish hospitals, national culture may provide another explanation for this finding. Three of Hofstede's [34] national culture dimensions, uncertainty avoidance, masculinity, and power distance, are applicable here. According to published data on these dimensions, Turkish professionals try to avoid uncertainty more than their U.S. counterparts (index value of 85 versus 46). U.S. managers are driven more by competition, achievement and success, as reflected in their masculinity index of 65 versus 45 in Turkey. Finally, for the power distance dimension, Turkish people are more willing to expect and accept the power of their managers rather than act on their own compared to Americans (index value of 66 versus 40). Thus, Turkish managers tend to use more of the established IT methods and technologies rather than trying newer innovations, such as decision support systems and supply chain systems. 
The organizational cultural profiles of Turkish hospitals were also investigated and the results are reported in Table 6 . Four profiles were described and the respondents were asked to distribute a total of 100 points within these profiles. None of the four profiles stand out. In fact, the first three profiles (dynamic \& entrepreneurial, personal \& extended family, and productionoriented) are divided about equally. Compared to the U.S. study[53], the formalized and production-oriented profiles are more prevalent in Turkey. This can be explained by the "power distance" dimension of national culture (i.e., reverence for authority and power). What is a bit surprising is the lower score associated with the personal \& extended family profile compared to that of the U.S. One would expect a higher score in a collectivistic and feminine society. A possible explanation is that contrary forces may be at play. The power distance dimension dominates in the work setting, and the collectivistic and feminine dimensions may not be so influential outside of social settings. Hence, issues such as alignment of policies and strategies of hospital staff, group collaboration systems, and training may not be perceived to be important.

Table 6

Cultural profile of Turkish hospitals.

\begin{tabular}{lllll}
\hline Sub culture $(N=91)$ & Mean & Median & Mode & St. Dev. \\
\hline Dynamic \& entrepreneurial & 27.20 & 25.00 & 30.00 & 14.93 \\
Personal \& extended family & 25.19 & 25.00 & 30.00 & 13.32 \\
Production-oriented & 24.12 & 25.00 & 25.00 & 15.75 \\
Formalized \& structured & 21.30 & 20.00 & 20.00 & 12.99 \\
\hline
\end{tabular}

\section{Top ten it issues based on location}

The survey participants were asked to specify the location of their healthcare organizations as either rural or urban. Researchers usually acknowledge the differences in the quality of healthcare provided, access, and resources available between rural and urban hospitals [26] and [58]. Many emphasize the need to increase the quality of healthcare delivery in rural areas by the effective use of information and communication technologies [26]. The Turkish Ministry of Health has also acknowledged this fact and has initiated the Healthy Villages Project, which aims to establish the necessary conditions for improved environment and health in villages [8]. Sixty-three respondents indicated that their hospitals were located in urban areas, while twenty-seven respondents indicated a rural hospital location. There are some salient differences in the top ten issues based on the location of the hospital, as shown in Table 7. 
Table 7

Key IT issues in urban and rural hospitals.

\begin{tabular}{lll}
\hline Issues & Urban $(N=63)$ mean $(\mathrm{SD})^{\mathrm{a}}(\mathrm{rank})$ & Rural $(N=27)$ mean $(\mathrm{SD})^{\mathrm{a}}$ (rank) \\
\hline Privacy of electronic health records & $1.48(1.35)(1)$ & $1.74(1.91)(2)$ \\
Quality assurance of health records & $1.52(1.42)(2)$ & $1.74(1.83)(1)$ \\
Security of electronic health records & $1.54(1.38)(3)$ & $1.78(1.90)(5)$ \\
Implementation of patient health record (PHR) & $1.68(1.68)(4)$ & $1.93(1.90)(8)$ \\
System wide approach to patient identity management & $1.73(1.50)(5)$ & $1.78(1.62)(3)$ \\
Change management from paper to electronic records & $1.78(1.53)(6)$ & $1.96(1.66)(9)$ \\
Disaster preparedness and recovery & $1.81(1.50)(7)$ & $2.00(1.98)(10)$ \\
Enhancing productivity in healthcare settings & $1.81(1.42)(8)$ & Not in top 10 \\
Training medical personnel on IT usage & $1.82(1.38)(9)$ & Not in top 10 10 \\
Reducing healthcare errors with information technology & $1.83(1.47)(10)$ & Not in top 10 \\
Compliance with regulations and laws & Not in top 10 & $1.78(1.84)(4)$ \\
Health information systems interoperability & Not in top 10 & $1.85(1.68)(7)$ \\
Implementation of electronic medical records & Not in top 10 & $1.85(1.72)(6)$ \\
\hline
\end{tabular}

a SD, standard deviations.

While the privacy of records was the most important issue in urban hospitals, quality assurance of health records was the most important issue in rural hospitals. Privacy of health records is important in all settings. However, security is a bigger concern in rural hospitals. A system-wide approach to patient identity management was among the top key issues in both urban and rural hospitals, underscoring these problems due to a lack of interoperability capabilities, regardless of geographical location. While enhancing productivity, training medical personnel and reducing healthcare errors were listed among the top ten issues only in urban hospitals. Compliance with regulations and laws, interoperability and implementation of EMRs were listed among the top ten only in rural hospitals. Hospital managers in cities seem to have problems with productivity and employee training. On the other hand, hospital managers in villages are more concerned with complying with regulations and implementing EMRs. It seems that rural hospitals are in the earlier stages of healthcare IT implementation than are urban because managers at rural hospitals are concerned with implementing EMRs, whereas hospital managers in urban areas are more concerned with implementing PHRs. For the most part, urban hospitals have largely completed or are well into the process of moving their medical records into electronic environments. Thus, change management and moving the medical records into the patient realm are now more important. On the other hand, rural hospitals are at the very early or even planning stages of implementing healthcare systems.

\section{Top ten it issues based on hospital type}

The Turkish law categorizes healthcare providers into three major types/stages. The first-stage providers are small clinics that do not offer inpatient services. The second-stage providers are hospitals offering most or all healthcare services, including inpatient services. Finally, third-stage providers offer all or most healthcare facilities and inpatient services as well as conduct research. University hospitals and research and development hospitals are usually classified in the third category. As a hospital's size increases in terms of number of employees and number of beds, its stage usually increases as well. Hence, larger facilities are usually classified as either second- or third-stage providers. As Keeler et al. [37] point out that larger urban research and teaching hospitals usually offer higher-quality healthcare services than smaller non-teaching and nonresearch institutions. Therefore, it is worthwhile to investigate the differences in the top ten IT issues based on hospital type. Twelve respondents categorized their hospitals in the first stage, sixty-four in the second stage, and fifteen in the third stage. Their results are presented in Table 8. 
Table 8

Key IT issues in different hospital types.

\begin{tabular}{|c|c|c|c|}
\hline Issues & $\begin{array}{l}\text { Stage } 1(N=12) \\
\text { mean }(S D)(\text { rank) }\end{array}$ & $\begin{array}{l}\text { Stage } 2(N=64) \\
\text { mean }(S D)(\text { rank })\end{array}$ & $\begin{array}{l}\text { Stage } 3(N=15) \\
\text { mean (SD) (rank) }\end{array}$ \\
\hline Quality assurance of electronic health records & $1.42(1.44)(1)$ & $1.48(1.34)(2)$ & $1.93(2.12)(4)$ \\
\hline Implementation of electronic medical records & $1.50(1.44)(2)$ & $1.69(1.61)(5)$ & $2.07(2.15)(6)$ \\
\hline Compliance with regulations and laws & $1.58(1.44)(3)$ & Not in top 10 & $1.93(2.08)(3)$ \\
\hline Change management from paper to electronic medical records & $1.64(1.80)(4)$ & $1.69(1.33)(6)$ & Not in top 10 \\
\hline Security of electronic health records & $1.67(1.72)(5)$ & $1.59(1.44)(3)$ & $1.87(2.10)(2)$ \\
\hline Information technology infrastructure issues & $1.67(1.72)(6)$ & Not in top 10 & $2.20(2.07)(10)$ \\
\hline Privacy of electronic health records & $1.67(1.72)(7)$ & $1.47(1.35)(1)$ & $1.93(2.08)(5)$ \\
\hline Enhancing productivity in healthcare settings & $1.73(1.55)(8)$ & $1.81(1.44)(9)$ & Not in top 10 \\
\hline IT support for healthcare supply chain & $1.75(1.42)(9)$ & Not in top 10 & Not in top 10 \\
\hline Health information systems interoperability & $1.75(1.42)(10)$ & Not in top 10 & $2.13(2.06)(7)$ \\
\hline System wide approach to patient identity management & Not in top 10 & $1.66(1.35)(4)$ & $2.13(2.10)(9)$ \\
\hline Utilizing IT to provide a safe work environment & Not in top 10 & $1.72(1.37)(7)$ & Not in top 10 \\
\hline Implementation of patient health record (PHR) & Not in top 10 & $1.78(1.54)(8)$ & Not in top 10 \\
\hline Training medical personnel on IT usage & Not in top 10 & Not in top 10 & $1.86(1.65)(1)$ \\
\hline Disaster preparedness and recovery & Not in top 10 & $1.84(1.53)(10)$ & $2.13(2.10)(8)$ \\
\hline
\end{tabular}

There are considerable differences in the top ten issues among hospitals in different stages. Quality assurance of electronic records was identified as the most important issue in stage 1 hospitals, privacy of electronic records was the most important in stage 2 hospitals, and training of medical personnel on IT usage was the top issue in stage 3 hospitals. While implementation of EMRs was the second most important issue for stage 1 hospitals, quality assurance and security of electronic records were the second most important issues in stage 2 and stage 3 hospitals, respectively. It can be argued that as hospital size increases, hospitals begin to get involved in research and development. Thus, the training of medical personnel on IT usage, compliance with regulations and security of medical records become more important. Small hospitals on, the other hand, seem to be more concerned with the quality, security and privacy of their medical records. Moreover, large hospitals seem to have less problems with IT infrastructure whereas small hospitals tend to have less concerns about interoperability, as they are typically standalone entities. Preparing for disasters and recovery of health records does not seem to be a concern of small hospital managers. However, this issue is important for second- and third-stage hospitals. Similarly, the implementation of PHRs seems to be important only for stage 2 hospitals. Stage 2 hospitals are the most common type of hospitals in Turkey, serving large volumes of patients. In addition, stage 2 hospitals generally operate under the guidance of the Turkish Ministry of Health. Hence, preserving patient health information within this large base and sharing this information with patients and other healthcare providers is critical to them.

\section{Discussion}

\subsection{Practical implications}

A scientific examination of healthcare IT issues provides a valid compilation of the pressing concerns surrounding the adoption of this promising technology. Investments in healthcare IT have the potential to reduce escalating healthcare costs, enhance the quality of service, improve safety and efficiency, and allow cost-effective, timely and patient-centered care [18] and [67]. However, if the challenges identified in this study are not addressed, these promises will go unfulfilled. In this regard, our findings have direct consequences for hospital administrators, vendors, policy makers and government authorities in Turkey.

As seen in Table 9, hospital management is affected by each challenge, and it must proactively address each one of them. While responses to some of these challenges are obvious, others 
require elaboration. For example, implementation and change management may require a variety of responses, such as planning, effective communication and training. Others may require stronger organizational monitoring and reinforcement. Note that vendors, policy makers, and government bodies also share responsibility for HIT adoption in Turkey. Vendors must strive to deliver higher-quality technology solutions to address the issues of privacy, security, and accuracy, and provide assistance in the implementation process. Policy makers in both the public and private realms must pay attention to issues of privacy, identity management, and healthcare regulations. Finally, government bodies can provide support and incentives for HIT implementation and enhancing productivity. A case in point is the American Recovery and Reinvestment Act (stimulus bill), which includes billions of dollars to encourage healthcare providers to adopt health information technology.

Table 9

Implications for stakeholders.

\begin{tabular}{llll}
\hline Issues & Hospital administration & Vendors & Policy makers \\
\hline Privacy of electronic health records & $\mathrm{x}$ & $\mathrm{x}$ & $\mathrm{x}$ \\
Quality assurance of electronic health records & $\mathrm{x}$ & $\mathrm{x}$ & $\mathrm{x}$ \\
Security of electronic health records & $\mathrm{x}$ & $\mathrm{x}$ & $\mathrm{x}$ \\
Implementation of electronic medical records & $\mathrm{x}$ & $\mathrm{x}$ & $\mathrm{x}$ \\
System-wide approach to patient identity management & $\mathrm{x}$ & $\mathrm{x}$ & $\mathrm{x}$ \\
Change management from paper to electronic medical records & $\mathrm{x}$ & $\mathrm{x}$ \\
Implementation of patient health records & $\mathrm{x}$ & $\mathrm{x}$ \\
Compliance with regulations and laws & $\mathrm{x}$ & $\mathrm{x}$ \\
Reducing healthcare errors with information technology & & \\
\hline
\end{tabular}

\subsection{Research implications}

Given the nascent emergence of healthcare IT, researchers have only recently begun to pay attention to healthcare information systems research. Key issue studies typically provide a starting point for researchers to focus on the important areas of concern and investigate them in greater depth. In this regard, research opportunities abound. One avenue of research would be to examine the critical issues from the perspective of different stakeholders, such as vendors, consumer groups, and governmental agencies[68]. These are important stakeholders in healthcare. Their views and a stakeholder analysis would yield greater understanding and insights. Stakeholder theory suggests that organizational strategies are geared toward balancing the conflicting goals of organizational stakeholders [30]. Thus, an analysis to reconcile the possibly different views of the stakeholders would be useful.

Worldwide, key issue studies in healthcare IT are sparse. Thus, this study establishes a framework for similar studies in other parts of the world, particularly in developing and underdeveloped nations. Once there is a critical mass of such studies, they may be repeated at regular intervals to trace the trends and evolution of healthcare IT, just like the studies that have been conducted in mainstream IS [43]. Thus, this study provides an important benchmark for similar studies in different parts of the world. Furthermore, every country has specific requirements, underlying legal frameworks, organizational cultures, national cultures and entrepreneurial orientations. These country studies must be interpreted in light of these contextual factors to develop a deeper understanding.

Finally, each critical issue represents a formidable inquiry on its own and researchers should explore each of them with greater vigor and intensity. For example, the implementation of 
EMRs, in spite of its potential benefits, has encountered numerous challenges in the U.S. (and elsewhere). These challenges include financial, organizational or behavioral, and technical barriers [63]. What are such challenges in other countries and how do they cope with them? There are numerous opportunities to learn from one another's experiences so that similar mistakes are not repeated.

\subsection{Implications for developing countries}

Our study offers valuable implications for developing nations and emerging economies of the world. Most of the top ten issues raised by Turkish health CEOs highlight the widespread lack of government action, data standards, plans, readiness for e-health and sufficient budgets for implementation processes [4]. The degree of politics, and lack of coordination and cooperation between health organizations' various departments and the bureaucracy, strict government tender systems in clinical health systems purchasing, and lack of resources (particularly of medical experts and expertise) are common factors hindering successful implementation and adoption of HITs in developing countries. Furthermore, as in Turkey, geographical barriers to accessing healthcare services, inequalities in the distribution of health personnel and high quality facilities, and informal payments are common problems faced by many developing nations [4], [35] and [54]. Alkraiji et al. [4] recently acknowledged that the immaturity of health data standards, and lack of a national plan and a recognized body are among the most significant reasons behind the difficulties in HIT implementation and adoption in Saudi Arabia. Aiming to address such barriers, the Turkish Health Transformation Program has achieved noticeable results, with enhanced implementation and adoption of HIT as well as improved productivity. The transformation program is still underway and more significant results, such as improved healthcare services and patient and health personnel satisfaction, may be realized in the coming years. Similar results would be achievable in other countries if attention were directed toward the critical issues highlighted in this study.

\subsection{Limitations}

As for the limitations of this study, the issues common to its survey methodology apply, e.g., sample size and representativeness. Although the sample could not be randomized due to the obvious difficulties in doing so, we achieved a fair amount of success in representing the larger hospitals in Turkey. The starting point for the key issue items was a U.S. instrument, but it went through significant revision in the Turkish context, adding to its validity and reliability. Other measures were directly adapted from the existing literature (i.e., organizational culture and entrepreneurial orientation). It should also be acknowledged that while the sample size was adequate, the response rate was somewhat lower. However, low response rates are endemic to healthcare IT research[32] as well as to developing countries.

\section{Conclusions}

Compared to the U.S. and many Western nations, Turkey presented these researchers with a unique opportunity to examine its healthcare IT issues. Turkey is a developing country with a distinct culture. Furthermore, Turkish healthcare is complex. It has a centralized structure through which a variety of healthcare providers serve patients. The government is the largest 
healthcare provider in the country. In this context, privacy, quality and security issues are among the top ten IT issues, as identified by hospital administrators. The next four issues are related to the implementation of different forms of electronic health records. The last three of the top ten issues are administrative in nature. The rankings can be explained by the conservative orientation of Turkish managers and their desire to avoid uncertainty. Additionally, the governmental impetus to transform healthcare through extensive IT use and implementation plays a role in the rankings. To the best of our knowledge, our study is the first to identify critical healthcare IT issues in a developing country. As such, it provides a unique perspective on these issues compared to studies conducted in advanced countries. This study's contributions are manifold. It provides important input to practitioners and policy makers in making decisions related to IT investments and implementation, and it give researchers investigating health IT issues in different parts of the world a benchmark and framework to work with.

\section{Acknowledgement}

The authors thank the Turkish Ministry of Health for their support in the survey administration process.

\section{References}

[1] T.I. Agartan. Marketization and universalism: crafting the right balance in the Turkish healthcare systems. Current Sociology, 60 (4) (2012), pp. 456-471

[2]. R. Akdağ. Health Transformation Program in Turkey and Primary Healthcare Services November 2002-2008. Turkish Ministry of Health, Health Publication Number: 770, Edition: November 2008 (2008)

[3] M. Alavi, D. Leidner. Knowledge management systems: issues, challenges, and benefits. Communications of the Association for Information Systems, 1 (7) (1999), pp. 1-36

[4] A. Alkraiji, T. Jackson, I. Murray. Health data standards and adoption process preliminary findings of a quantitative study in Saudi Arabia. Campus-wide Information Systems, 28 (5) (2011), pp. 345-359

[5] Anonymous/ Hospitals Deaths from Medical Errors at 195,000 per Year USA. medicalnewstoday.com (2004) Available from: http://www.medicalnewstoday.com/releases/11856.php (accessed 14.05.12)

[6] Anonymous. Tibbi hatalar Olum Nedenleri Arasinda Ilk Beste. medimagazin.com.tr (2009) Available from: http://www.medimagazin.com.tr/hekim/genel/tr-tibbi-hatalar-olum-nedenleriarasinda-ilk-beste-2-12-13893.html (accessed 14.05.12)

[7] A. Arslan. Saglık Sektorunde Rekabetciligin Anahtarı BIT. Bilgicagi.com (2009) Available from: http://www.bilgicagi.com/Yazilar/2429saglik_sektorunde_rekabetciligin_anahtari_bit.aspx (accessed 14.05.12) 
[8] S. Aydın, T. Buzgan, H. Demirel, F. Gündüz. Healthcare Transformation Program in Turkey and Primary Healthcare Services. Turkish Republic Ministry of Health Publications No. 770, November 2008 (2008)

[9] L. Ball, R. Harris. SMIS members: a membership analysis. MIS Quarterly, March (1982), pp. $19-38$

[10] C. Barut. Onumuzdeki Dort Yilda Elektronik Tibbi Kayıt Kullaniminin Iki Katina Cikmasi Bekleniyor. medimagazin.com.tr (2011) Available from: http://www.medimagazin.com.tr/anasayfa/dis-haberler/tr-onumuzdeki-dort-yilda-elektronik-tibbi-kayit-kullaniminin-iki-katinacikmasi-bekleniyor-1-76-32890.html (accessed 14.05.12)

[11] A. Bhattacherjee, N. Hikmet. Physicians' resistance toward healthcare information technologies: a dual factor model. Proceedings of the 40th Hawaii International Conference on System Sciences (2007), pp. 1530-1605

[12] D.J. Brailer. Interoperability: the key to the future healthcare system. Health Affairs, 15 (9) (2005)

[13] S.M.A. Burney, N. Mahmood, Z. Abbas. Information and communication technology in healthcare management systems: prospects for developing countries. International Journal of Computer Applications, 4 (2) (2010), pp. 27-32

[14] A. Can, H. Ibicioğlu. Yonetim ve Yoneticilik Yonunden Universite Hastanelerinin Degerlendilmesi. Suleyman Demirel Universitesi Iktisadi ve Idari Bilimler Fakultesi Dergisi, 13 (3) (2010), pp. 253-275

[15] M.C. Christensen, D. Remler. Information and communication technology in us healthcare: why is adoption so low and slow is better? Journal of Health Politics, Policy and Law, 34 (6) (2009), pp. 1012-1034

[16] DATAMONITOR. Country Analysis Report: Turkey - In-Depth PESTLE Analysis. (2009) (publication date: August 2009)

[17] D. Davis, J. Adams. IT strategic planning what healthcare CFOs should know. Healthcare Financial Management (November) (2007), pp. 100-104

[18] P.K. Dey, S. Hariharan, W. Ho. Managing healthcare technology in quality management framework. International Journal of Technology Management, 40 (2007), pp. 45-68

[19] G.W. Dickson, R.L. Leithesier, J.C. Wetherbe. Key Information Systems Issues for the 1980's. MIS Quarterly (September) (1984), pp. 135-159. Full Text via CrossRef

[20] R.B. DiPietro, Y. Wang. Key issues for ICT applications: impacts and implications for hospitality operations. Worldwide Hospitality and Tourism Themes, 2 (1) (2010), pp. 49-67 
[21] DPT. Knowledge Society Action Plan. Undersecreteriat of State Planning Organization (DPT) (2006) (in Turkish), Available

from: http://www2.dsi.gov.tr/splan/ktmllite/files/uploads/pdf_dosyalar/bilgi\%20_toplumu_eylem _plani_iliskisi.pdf (accessed 14.05.12)

[22] M. Dündar, A.S. Uzak, Y. Karabulut. Healthcare in overview of Turkey. EPMA Journal, 1 (2010), pp. 587-594

[23] G. Dussault. The healthcare professions and the performance of future health systems in low income countries: support or obstacle? Social Science \& Medicine, 66 (2008), pp. 2088-2095

[24] Er Ünal. Sağlık Hukuku [Health Legislation]. Savaş Yayınevi, Ankara (2008) (in Turkish)

[25] J.D. Ford, L.W. Ford. Decoding resistance to change. Harvard Business Review, 87 (4) (2009), pp. 99-103

[26] M.P. Gagnon, J. Duplantie, J.P. Fortin, R. Landry. Implementing telehealth to support medical practice in rural/remote regions. Implementation Science, 1 (18) (2006), pp. 1-18

[27] D. Garets, M. Davis. Electronic Medical Records vs. Electronic Health Records. A HIMSS Analytics White Paper (2006)

[28] I. Gostin. Healthcare information and the protection of personal privacy: ethical and legal considerations. Annals of Internal Medicine, 127 (8) (1997), pp. 683-690

[30] M.J. Hatch. Organization Theory: Modern, Symbolic and Postmodern Perspectives. Oxford University Press, Oxford, UK (1997)

[31] A.H. Hennington, B.D. Janz. Information systems and healthcare XVI: physician adoption of electronic medical records: applying the UTAUT model in a healthcare context.

Communications of the Association for Information Systems, 19 (2007), pp. 60-80

[32] N. Hikmet, S.K. Chen. An investigation into low mail survey response rates of information technology users in healthcare settings. International Journal of Medical Informatics, 72 (1) (2003), pp. 29-34

[34] G. Hofstede. Culture's Consequences: International Differences in Work-Related Values. Sage, Newbury Park, CA (1980)

[35] J. Holst, C.A. Gericke. Review: healthcare financing in Yemen. International Journal of Health Planning and Management, 27 (2012), pp. 198-225

[36] P.J. Hu, P.Y.K. Chau, O.R.L. Sheng, K.Y. Tam. Examining the technology acceptance model using physician acceptance of telemedicine technology. Journal of Management Information Systems, 16 (2) (1999), pp. 91-112 
[37] E.B. Keeler, L.V. Rubenstein, K.L. Kahn. Hospital characteristics and quality of care. Journal of the American Medical Association (268) (1986), p. 1709

[38] J. Leviss, R. Kremsdorf, M. Mohaideen. The CMIO - a new leader for health system. Journal of the American Medical Informatics Association, 13 (5) (2006), pp. 573-578

[39] K. Lewin. Frontiers in group dynamics: concept, method and reality in social sciences, social equilibria and social change. Human Relations, 1 (1947), pp. 5-41

[40] M. Lluch. Helathcare professional's organisational barriers to health information technologies - a literature review. International Journal of Medical Informatics, 80 (2011), pp. 849-862

[41] N.M. Lorenzi, R.T. Riley. Organizational issues = change. International Journal of Medical Informatics, 69 (2003), pp. 197-203

[42] J. Luftman, T. Ben-Zvi. Key issues for IT executives 2009: difficult economy's impact on IT. MIS Quarterly Executive, 9 (1) (2010), pp. 49-59

[43] J. Luftman, T. Ben-Zvi. Key issues for IT executives 2011: cautious optimism in uncertain economic times. MIS Quarterly Executive, 10 (December (4)) (2011), pp. 203-212

[44] J. Luftman, R. Kempaiah. Key issues for IT executives 2007. MIS Quarterly Executive, 7 (2) (2008), pp. 99-112

[45]. J. Luftman, R. Kempaiah, E.H. Rigoni. Key issues for IT executives. MIS Quarterly Executive, 8 (3) (2009), pp. 151-159

[46] D. Miller. The correlates of entrepreneurship in three types of firms. Management Science, 29 (7) (1983), pp. 770-791

[47] H. Moghaddasi, A. Sheikhtaheri. CEO is a vision of the future role and position of CIO in healthcare organizations. Journal of Medical Systems (34) (2010), pp. 1121-1128

[48] N. Ömürbek, F.G. Altın. Sağlık Bilişim Sistemlerinin Uygulamasına İlişkin Bir Araştırma: İzmir Örneği. SDÜ FED Fakültesi Sosyal Bilimler Dergisi, 19 (2009), pp. 211-232

[49] M. Özata, H. Altunkan. Hastanelerde Tıbbi Hata Görülme Sıklıkları, Tıbbi Hata Türleri ve Tıbbi Hata nedenlerinin Belirlenmesi: Konya Örneği. Tıp Araştırmaları Dergisi, 8 (2) (2010), pp. $100-111$

[50] B. Özdeniz. Turkish healthcare: overview of the health system. ICU Management, 4 (2010), pp. $36-38$ 
[51] H. Özgen, A. Öztürk. Türkiye'deki Devlet Hastanelerinin Yönetim ve Organizasyon Yapısını Verimlilik Açısından İnceleyen Bir Çalışma. Sosyal Siyaset Dergisi, 1 (8) (1992), pp. 27-37

[52] S. Özgener, F. Kü̧̈ük. Hastanelerde Modern Yönetim Felsefesinin Verimliliğe Etkisi: Gevher Nesibe Hastanesinde Bir Uygulama. Selçuk Üniversitesi Sosyal Bilimler Enstitüsü Dergisi (19) (2008), pp. 341-358

[53] P. Palvia, K. Lowe, H. Nemati, T. Jacks. Information technology issues in healthcare: hospital CEO and CIO perspectives. Communications of the Association for Information Systems, 30 (May (1)) (2012), pp. 293-312 (Article 19)

[54] A. Pearson, Z. Jordan. Evidence based healthcare in developing countries. International Journal of Evidence-Based Healthcare, 8 (2010), pp. 97-100

[55] S. Reinberg. US Health Care Spending to Double by 2017, Reports Predicts. The Washington Post (2008) Available from: http://www.washingtonpost.com/wpyn/content/article/2008/02/26/AR2008022601380.html (accessed 15.05.12)

[56] Sağlık Bakanlığı. Action Plan of Turkish Healthcare Information Systems - Ministry of Health (2004) (in Turkish), Available from: http://www.saglik.gov.tr/extras/birimler/bidb/tsbs.pdf (accessed 14.05.12)

[57] I. Sahin, Y.A. Ozcan, H. Ozgen. Assessment of hospital efficiency under health transformation program in Turkey. Central European Journal of Operations Research, 19 (2011), pp. 19-37

[58] K. Sheikh, C. Bullock. Urban-rural differences in the quality of care for Medicare patients with acute myocardial infarction. Archives of Internal Medicine, 161 (2001), pp. 737-743

[59] D.C. Strasser, S.J. Smits, J.A. Falconer, J.S. Herrin, S.E. Bowen. The influence of hospital culture on rehabilitation team functioning in VA hospitals. Journal of Rehabilitation Research and Development, 39 (1) (2002), pp. 115-125

[60] TUBITAK. Vizyon 2023 Projesi (2001) Available from: http://www.tubitak.gov.tr/tubitak_content_files/vizyon2023/si/EK-21.pdf (accessed 14.05.12)

[61] TUIK. Turkiye Sağlık Istatistikleri (2012). Available from: http://www.tuik.gov.tr/PreTablo.do?tb_id=6\&ust_id=1 (accessed 14.05.12)

[62] N. Varol, O. Saka. Healthcare and pharmaceutical policies in Turkey after 2003. Eurohealth, 14 (4) (2008), pp. 29-32 
[63]. K.A. Wager, F.W. Lee, J.P. Galser. Healthcare Information Systems (second ed.)JosseyBass, San Francisco, CA (2009)

[64] R. Ward, C. Stevens, P. Brenthall, J. Briddon. The attitudes of healthcare staff to information technology: a comprehensive review of the research literature. Health Information \& Libraries Journal, 25 (2008), pp. 81-97

[65] J.P. Weiner, T. Kfuri, K. Chan, J.B. Fowles. 'e-Iatrogenesis': the most critical unintended consequence of CPOE and other HIT. Journal of American Medical Information Association, 14 (3) (2007), pp. 387-389

[66] World Health Organization (WHO). World Health Report 2006: Working Together for Health. WHO, Geneva (2006)

[67] M. Wynia, K. Dunn Dreams and nightmares: practical and ethical issues for patients and physicians using personal health records. Journal of Law, Medicine \& Ethics (2010), pp. 64-73

[68] S.M. Thompson, M.D. Dean. Advancing information technology in healthcare Communications of the ACM, 52 (6) (2009), pp. 118-121

1. An interview with Ayşegül Avcı and Mahir Ülgü, Information Systems experts at the Department of Information Systems at the Turkish Ministry of Health.

2. National statistics by urban/rural location and type of hospital are not readily available. No known classification exists based on rural and urban location. Since Turkey is a fast developing country; the nature of cities is changing and the country is urbanizing rapidly.

3. Hurricane Sandy in October 2012 caused much havoc in New York hospitals, destroying medical equipment and research facilities. In the NYU Langone Medical Center, electronic medical records were protected by a server in New Jersey. 